\title{
Regulation of Tertiary Education
}

\section{Malcolm Abbott}

$\mathrm{T}$ The provision of tertiary education is regarded by many as being vital to both the achievement of economic success and greater social equity. In recent years the trend in most countries has been to grant government education providers with greater institutional autonomy but at the same time subject them, and private providers, to formal regulation. The impact of this regulation to both government and private providers is little understood by participants and in most countries is still in an evolutionary stage.

The collapse in 2003 in New Zealand of two major private tertiary education providers (PTEs) - Modern Age Institute of Learning and Carich Limited brought into question in that country the manner in which PTEs are regulated. In New Zealand PTEs make up a significant proportion of the tertiary education sector (in July 2003 there were 49,897 students formally enrolled in PTEs or around 15 per cent of formal enrolments; 337,004; Table 1). In New Zealand PTEs are able to offer certificate, diploma and degree level qualifications; both developed by themselves and by the national accreditation authority. In providing these services they must submit themselves to a national regulatory regime that is designed to enforce quality standards; not just of the PTEs but also of a number of government tertiary education providers (GTEs). In New Zealand GTEs include the universities, polytechnics, institutes of technology, colleges of education and wananga. In this paper the term GTE is not applied to the universities but only to the polytechnics, colleges of education and wananga because these institutions fall under the same regulatory regime as the PTEs, which the universities do not.

The purpose of this paper is to identify the economic rationale for the regulation of PTEs and discuss whether New Zealand's regulation of this sector effectively achieves economically rational outcomes. Internationally many countries are opening up their tertiary education sectors to increasing levels of competition; both between government-owned institutions and between private institutions and the government sector. At the same time the creation and operation of formal regulation of the tertiary education sector has become a matter of contention. The regulatory dilemmas facing the New Zealand Government provides a good example of some of the problems faced by governments when they attempt to create a regulatory framework for the tertiary education sector.

In the first section the general background to the New Zealand tertiary sector is provided. In the following section a description of the economic rationale for the regulation of the tertiary education sector is given, and in the next section the responsibilities of the New Zealand Qualification Authority (NZQA), which enforces regulation is explained. A discussion of whether NZQA's regulations

Malcolm Abbott is Dean of the School of International Studies at AIS St Helens, a private tertiary education institution in Auckland, New Zealand. 
adequately address the economic reasons for regulation is then provided and some comments are made more generally about the nature of tertiary education regulation.

\section{Background}

Education and training - through the creation of human capital - is considered to be an important part of the development of any economy (Organisation for Economic Cooperation and Development, 2002). In New Zealand, the present structure of the tertiary education sector was formally created during the late 1980s. Prior to 1989 the New Zealand tertiary education sector, like many around the world, was dominated by a number of government-owned providers. The colleges of education provided teacher training programs, the polytechnics certificate and diploma programs and the universities degree and postgraduate degree programs. At that time, therefore, government-owned polytechnics, colleges of education and universities did not compete directly with each other, nor was the state sector subject to substantial competition from PTEs.

During the 1980s, the New Zealand's tertiary education system was examined by a wide range of government bodies. These examinations and their reports culminated with two Department of Education (1989) policy documents Learning for Life and Learning for Life II. The policy documents made two main recommendations, which were subsequently largely implemented.

The first was that there should be a substantial increase in the number of New Zealanders undertaking tertiary education study in order to raise the general skill level of the workforce. Since 1989 this was substantially achieved with the number of domestic students enrolled in tertiary education growing from 172,190 in 1990 to 302,089 in 2003. The growth in student numbers produced an overall increase in the proportion of the New Zealand population formally enrolled in tertiary education from 4.9 per cent in 1991 to 7.5 per cent in 2003.

The second main recommendation was that a greater level of competition should be brought into the system. One of the ways in which this was pursued was to give GTEs much greater autonomy than they had previously enjoyed. As a result, they have been able to compete directly with universities in delivering degree programs. As well they have been allowed to establish campuses in centres outside their 'home' locality in direct competition with other GTEs and in many cases have begun to attract overseas students.

Since 1989 nearly all of the polytechnics have established programs in centres besides their home locality. The trend has been for the smaller regional polytechnics to establish centres either in larger cities like Auckland or Christchurch or alternatively in smaller towns in their own regions. A good example of this is the Southern Institute of Technology based in Invercargill, which established campuses in Christchurch and in Gore (a small regional centre in Southland).

In 2003, as a direct result of these changes, there were 19,680 students (20.1 per cent of total formal enrolments) enrolled in degree level programs in 
polytechnics - in 1989 there were no such enrolments as the polytechnics did not offer degree level programs. This number does not include those at the Auckland University of Technology, which was converted from a polytechnic to a university in 1999. In 1989 this institution had no degree level students. By 2003 it had 9,353 undergraduate and 454 postgraduate equivalent full time students (Auckland University of Technology, Annual Report). As well in 2003 there were 7,296 overseas students enrolled in the polytechnics, the number being negligible in 1989 (Ministry of Education, Education Statistics).

As part of the process of greater autonomy to the GTEs, the Education Amendment Act 1989 provided for an annual allocation of funds to each GTE, which could be used by the GTEs to pay staff, own buildings and meet other commitments. A pool of contestable funds was also established which the GTEs or PTEs could apply for. Within the limit of their Charters and the funds available to them, the GTEs were free to plan their own destinies. By making the GTEs autonomous and funding them according to the students they attracted, it was hoped they would become more market-oriented and more responsive to the needs of students and industry. At the same time PTEs in New Zealand were given greater opportunities to compete with the GTEs in the education and training market (Abbott, 2000; McKenzie, 1996).

Table 1: Student Numbers in Tertiary Education: New Zealand 1991 to 2003

\begin{tabular}{|c|c|c|c|c|c|c|}
\hline & 1991 & 1995 & 1998 & 2000 & 2002 & 2003 \\
\hline Polytechnics & 72,911 & 94,389 & 95,319 & 87,436 & 95,782 & 98,072 \\
\hline Colleges of Education & 8,073 & 12,645 & 10,637 & 12,045 & 10,788 & 10,828 \\
\hline Universities & 94,166 & 104,525 & 118,995 & 122,727 & 132,396 & 137,007 \\
\hline Wananga & -- & 509 & 1,431 & 2,972 & 27,535 & 41,200 \\
\hline PTEs & -- & -- & 28,712 & 39,173 & 53,385 & 49,897 \\
\hline Total & 175,150 & 212,068 & 255,094 & 264,353 & 319,886 & 337,004 \\
\hline International students & 2,960 & 6,742 & 8,430 & 11,638 & 26,878 & 34,915 \\
\hline $\begin{array}{l}\text { Proportion of total } \\
\text { (per cent) }\end{array}$ & 1.7 & 3.2 & 3.3 & 4.4 & 8.4 & 10.4 \\
\hline Domestic students & 172,190 & 205,326 & 246,664 & 252,715 & 393,008 & 302,089 \\
\hline $\begin{array}{l}\text { Proportion of } \\
\text { population (per cent) }\end{array}$ & 4.9 & 5.6 & 6.5 & 6.6 & 7.4 & 7.5 \\
\hline
\end{tabular}

Source: Tertiary Education Commission (2003) 
In terms of efficiency it would appear that the major concern on the part of the government was to achieve a more efficient allocation of resources, as well as promote dynamic efficiency. Consequently, it was envisaged that the introduction of enhanced competition was going to lead to the allocation of resources into the delivery of programs that were in greater demand by students as well as to the dynamic development of new programs. There seems to have been less concern about achieving efficiencies in the operation of the providers themselves, although it is likely this also has occurred (Abbott and Doucouliagos, 2000).

At a regulatory level the Department of Education, which had previously been responsible for the administration of tertiary education in New Zealand, was abolished and replaced by a Ministry which was to be responsible only for overall policy. A Tertiary Education Commission was later established with the responsibility for the distribution of government funds to the various education providers.

As part of the reform process a national qualifications authority (the New Zealand Qualifications Authority) was also established to replace governmentfunded bodies like the Trades Certification Board, the Authority for Advanced Vocational Awards and Vocational Training Board, which had previously been responsible for controlling standards, analysing training needs and conducting examinations. Under the old system the boards were comprised of representatives of professional and technical bodies, together with educational professionals and were responsible for prescribing courses, and setting and marking examinations. Although each of the polytechnics conducted the teaching of many courses, successful graduates from each course received New Zealand Certificates irrespective of where they were trained.

Since June 1990, subject to accreditation and validation by the NZQA, the GTEs and PTEs have been free to develop their own courses - NZQA also retained responsibility for prescribing some courses, but GTEs and PTEs are not bound to adopt them.

The regulation of the tertiary education sector by NZQA spreads across the activities of both GTEs and PTEs and even to the universities when they deliver national qualifications. The universities' degrees and higher degree programs, however, are not subject to NZQA regulation, but are overseen by the New Zealand Vice-Chancellors' Committee.

This process of giving tertiary education institutions greater autonomy, and then subjecting them to external formal regulation that provides quality assurance processes has become a feature of number of countries during the 1990s (Dill, 1997, 2000; Mora, 2001).

In countries such as the United Kingdom, Australia, the United States and New Zealand, where universities have traditionally been fairly autonomous bodies there has been an increase in the degree to which they are formally 'audited' by statutory bodies. In countries such as those in continental Europe where the universities have a strong history of state control there has been a movement toward greater university autonomy (Mora, 2001). In both cases, therefore, there has been a tendency for universities to have a degree of autonomy from the 
government and be influenced by market pressures while at the same time be subjected to quality assessment and assurance systems.

In the New Zealand tertiary education sector both trends have occurred. The rigid control of the Education Department of the polytechnics was replaced by a system of institutional autonomy, subject to regulation. At the same time the autonomy of the universities has been eroded by the implementation of the accreditation processes of the New Zealand Vice-Chancellors' Committee.

The granting of greater autonomy to the GTEs has meant that a number have changed greatly in character. In particular, the granting of the opportunity to deliver degree programs has meant that the process of 'academic drift' in a few of the larger polytechnics has occurred at a rapid rate. After 1989 at the Aucklandbased UNITEC Institute of Technology and Auckland Institute of Technology (now known as the Auckland University of Technology) degree students quickly outnumbered sub-degree students.

Across the system, the proportion of students studying for degrees rose markedly and part-time student numbers plummeted. As mentioned earlier around 20 per cent of students enrolled in polytechnics were degree or postgraduate degree students by 2003. In particular there has been strong growth in enrolments in business degree programs in the polytechnics as well as in disciplines such as health studies (particularly nursing), information technology, communication and education. In a lot of cases the process involved the upgrading of diploma level programs to degree level.

This strong movement of the GTEs into degree level programs would seem to indicate that there was indeed a fair amount of demand for degree level courses that before 1989 was not being met by the universities. The abrupt change in the nature of a number of GTEs would indicate that a more optimal allocation of resources away from sub-degree programs and into degree programs was met by the reforms.

One characteristic of the New Zealand education and training sector in the 1990s has been the growth of PTEs that have moved very substantially into the sub-degree sector of post-school education, as well as into the provision of degree programs and even MBAs. By 2003 there were 49,897 formal enrolments in PTEs in New Zealand, the bulk of these being at the sub-degree level (Ministry of Education, Educations Statistics indicate there were 1,987 degree enrolments and 648 postgraduate enrolments). Thus GTEs have become subject to a level of competition that they did not experience prior to 1989. These changes have meant that students now have a greater choice of provider. Presumably, the growth of the PTEs was in response to demand by students that was not being met by the GTEs. The tertiary education sector in 1990s, therefore, could be said to be more dynamic in its response to changes in student demand than it had been before 1989.

Overall the competitive climate in which New Zealand's tertiary education providers operate has increased throughout the 1990s. This has meant that they have been facing more intense pressure both to meet directly the demands of students and to operate at a higher level of efficiency. Even with these changes, 
however, it should be recalled that the process has been one of partial deregulation of the tertiary education sector rather than a full deregulatory reform. The major tertiary education providers in New Zealand are still the government-owned universities and polytechnics, and approximately half of the tertiary education funding comes from government subsidies. Furthermore since 2001 government funding of the PTEs has been capped. Finally the GTEs and the PTEs are subject to regulation by NZQA.

\section{Market Failures and Economic Regulation}

Given the still extensive regulation of the New Zealand tertiary education sector it is instructive to remind ourselves what the economic rationale for regulation is. The economic justification for regulation of private businesses is generally that it may help to overcome some sort of market failure, which leads to sub-optimal outcomes.

One of the main types of market failure that justifies government intervention is where a good or service has 'pure' public good characteristics. A pure public good is one, whose consumption has the characteristics of being non-rival and non-exclusive (Pindyck and Rubinfeld, 1998). A good is non-rival if consumption by one person does not restrict its availability for consumption by others (that is, additional consumption does not add to costs). A good is non-exclusive if its availability to one person makes it also available to anyone else who wants to use it. As a consequence, it is difficult, or impossible, to charge people for using nonexclusive goods - the goods can be enjoyed without direct payment. The classic example of a pure public good is national defence. Defence is non-exclusive since once a nation provides for its defence all of its citizens enjoy its benefits. Defence is also non-rival in that the marginal cost of providing it to an additional person is zero.

Education is fundamentally a privately consumed good as it is exclusive, but may be considered a quasi-public good if a significant amount of benefits or costs (externalities) flow from its production or consumption such that they affect third parties. In the past the possible existence of positive externalities that flow from education has been used to justify the subsidisation of both government and private providers of tertiary education and training (Maglen, 1990; Quiggin, 1999; Gemmell; 1997). Studies have been conducted on this issue in the New Zealand case and have generally found that positive externalities exist; although not to the extent of covering as high a level of costs as is presently the case (see for instance Maani 1997; Boston 1994). Even if it justifies some subsidy of tertiary education, the existence of externalities does not provide us in this case with any justification for the direct regulation of the PTEs or indeed the government-owned providers. Instead economic justification must be found elsewhere.

Besides the existence of externalities another possible source of market failure may arise from information asymmetry; that is where most consumers have little ability to reliably gauge the quality of a particular product or service. If this is the case, it may then be possible that the resulting resource allocation is less 
efficient than if consumers are fully informed. It is possible that information asymmetries are relevant when looking at the regulation of tertiary education markets, if consumers are sufficiently ill informed then it might adversely affect resource allocation and if there are ways in which the government might improve this situation.

For students to make rational choices about which qualification they would like to enrol and study in it would be thought necessary for them to have sufficient information about the quality of the alternative courses available to them. Although it may be possible that they have some information about the general reputation of providers like the older universities in New Zealand, in general students would not be expected to have a very substantial knowledge about the standards of many of the other tertiary education providers. It is quite possible that students might like to undertake shorter and even low quality courses if the cost was less than high quality qualifications. At times the distinction between the quality of the various courses at different providers may be hard to distinguish.

Another area where information may be deficient is in the case of risk. Often students undertake qualifications that can extend over a number of years. In New Zealand, for instance, most degree qualifications take three years of study to complete. Students who commit their funds and time to courses of study of this length might be concerned if there is some degree of financial uncertainty facing the provider of their choice.

A third possible cause of market failure is the risk of third-party losses in tertiary education markets due to systemic instability. Systemic instability occurs when breaches of promises by one institution cause distress to other institutions that are well managed and commercially sound. In financial markets this instability has been used as a rationale for the establishment of regulation in the form of prudential supervision (Neal, 1997).

In tertiary education markets systemic instability can be created at two levels. First of all it may occur when the demise of a provider within, say, the PTE sector may encourage students to withdraw from all providers in this sector. The collapse of Carich and Modern Age for instance may have made students hesitant to choose PTEs more generally. Certainly the growth of the PTEs has slackened off since the demise of these two institutions although this may be due to a range of other factors beside the fallout from their collapse. An indication of the degree to which PTEs are sensitive to the collapse of institutions like Carich and Modern Age was the willingness of a number of the PTEs to enrol students from these institutions after their demise, in some cases incurring a loss in the process.

Second, it may affect the tertiary education sector at the national level. In July 2003 there were 34,915 international students enrolled in New Zealand tertiary education providers. The collapse of a single very large provider in New Zealand could lead to a general aversion on the part of international students to study at all New Zealand tertiary education providers.

The possibility of a growing aversion by overseas students for New Zealand tertiary education institutions, because of the adverse publicity surrounding the Carich and Modern Age collapses, has been a particular concern of Government 
authorities during 2003 and 2004. During 2004 there has been a fall off in the number of overseas students applying - approved applications to the Immigration Services falling from 115,223 in 2002-03 to 102,511 in 2003-04 (New Zealand Immigration Service, 2004). This could be due to a range of factors including the rise in the value of the New Zealand dollar, changes in immigration regulations in New Zealand and abroad as well as the degree of competition from other countries as well as the adverse publicity surrounding the collapse of the two private providers. Determining which of these factors has been the most important is difficult but the latter has certainly made some contribution.

Bearing in mind the possibility of information asymmetry and systemic instability it is possible to judge the degree to which the New Zealand regulatory regime counters these possible causes of market failure.

\section{New Zealand Tertiary Education Regulation}

The main regulator of the New Zealand tertiary education market is the NZQA; a central government statutory authority established under the Education Amendment Act 1989. The role of the NZQA is to provide a framework for the development of quality assured qualifications. This means that the NZQA both develops national qualifications and oversees the providers that deliver them. As well as registering the qualifications of the PTEs and GTEs it gives approval to their introduction and audits their delivery. In addition the NZQA has other functions such as the evaluation of overseas qualifications for immigration and employment purposes and it is accountable through the Minister of Education to Parliament. The NZQA does not deal in the funding of providers, which is the responsibility of the Tertiary Education Commission.

As part of its functions the NZQA has established a Register of Quality Assured Qualifications, which provides information for students about the quality assured qualifications that exist in New Zealand. These include both NZQA qualifications and also those independently established by the universities. The creation of the Register would appear to go some way to providing students with a degree of information about the range of qualifications in New Zealand, as well as the degree to which these qualifications meet pre-set standards.

By developing a National system of qualifications students are able to ascertain the nature of courses offered by the various providers. The New Zealand Diploma of Business, for instance, is a qualification developed by the NZQA but delivered by range of universities, GTEs and PTEs. The providers are monitored and audited by the NZQA when they offer courses for these qualifications. Students, therefore, have an idea about the content and nature of the qualification regardless of where it is offered.

This process of registration and delivery of national qualifications helps to reduce the problems of information asymmetry. It is, however, an assurance that minimum requirements are met and provides no more information about the level of quality achieved. The Register, for instance, provides no information on the relative standing of providers, such as a number of international higher education 
rankings do. Furthermore it provides students with little information about the basis by which the regulator judges accreditation standards. Students are given an indication accredited providers meet a regulated minimum standard but are given no indication of what that minimum might be.

Licensing and an insistence on a minimum degree of competence is a common response on the part of governments in situations where it is difficult for members of the public to gain reliable independent information about the quality of a product or service. In New Zealand for instance electricians, plumbers, doctors and dentists all have to be registered with a legislated registration board. The general purpose of this approach is to ensure that consumers are able to be certain that professional service providers meet certain standards.

One difficulty with this type of regulation is that it can often either impose a significant burden on providers, which is then passed onto consumers in the form of added costs and prices, or can be used by providers to exclude entry into the market. This can occur in the cases where the costs of meeting the licensing requirements are too burdensome, which then can have the effect of restricting competition by making new entry too difficult.

In the case of the NZQA's regulation, there is little evidence that NZQA developed qualifications impose a significant burden on providers. Given that these qualifications are now offered by a large number of providers, both private and government-owned, entry requirements do not appear to be unduly restrictive. In the case of PTE and GTE developed qualifications the situation is a little unclear, although it should be noted that over the past ten years there has been a very strong development of new degree programs on the part of the GTEs. This at the very least implies that the entry of new government providers into these undergraduate level qualifications is not impossible.

The NZQA regulation does not appear to give students any additional knowledge about the degree of risk associated with different providers. In the case of the GTEs and universities it would be expected that the government would bail out any of them that get into financial difficulties, as was the case with the Taranaki Polytechnic in 2001. In the case of the PTEs there is no particular regulation imposed by the NZQA that ensures prudent commercial behaviour on the part of a provider in the way that prudential supervision of the financial sector does. NZQA's regulation instead concentrates more on establishing and maintaining the quality of programs rather than giving students any knowledge about the degree of risk involved in enrolling with any particular institution. There are however some provisions in the regulations of PTEs that provide students with some protection.

The NZQA has two requirements within its quality assurance standards for PTEs that relate to the protection of student fees. The first requirement protects students who choose to withdraw from a course within seven days of it starting. PTEs must place fees in an independent trust fund for this period. The second and more important provision requires PTEs to arrange protection of student fees in the event of insolvency, regulatory or voluntary closure of the provider. NZQA 
allows for a range of different alternative provisions to be acceptable. These measures include that:

- $\quad$ students pay their fees after they receive tuition;

- fees are paid into an independent trust fund;

- $\quad$ insurance policies that protect against the loss of education fees be purchased;

- $\quad$ providers use fees to purchases guarantees and bonds; or finally

- PTEs have a collaborative arrangement with other providers such that students can complete their education elsewhere.

None of these arrangements strictly speaking eliminates the possibility of systemic instability occurring. Instead the measures are designed to protect students in the event of institutional failure. They do not make institutional failure any less likely.

The failure of an institution is not necessarily a bad thing. After all one of the generally accepted benefits of a market is that there is a tendency for productively inefficient operators to be either forced from the market or taken over by more efficient operators. Resources can then be reallocated to providers, which achieve a greater level of productive efficiency. The problem of systemic instability means that the regulator must prevent this institutional failure spreading to other providers. At the same time it must avoid committing itself to the financial support of institutions in that this can lead to the added difficulty of 'moral hazard' - that is, the possibility that by promising to financially support institutions in difficulty it might make this more likely by encouraging commercially risky activity.

In the case of the collapse of Modern Age and Carich, the NZQA acted to facilitate the transfer of students from the failed providers to others so that they could complete their qualifications at no extra cost. This process is greatly assisted if the PTE's qualifications mainly consisted of National Qualifications that other providers deliver. Effectively, what this does is to eliminate the risk to students of attending a PTE. Theoretically, systemic instability should not then exist if students perceive that the qualifications they are studying for are not tied entirely to the financial success or failure of the provider. If students have this perception then they should not feel as threatened by the collapse of another provider besides their own. The successful transfer of Carich's students to other providers might even lead to a reduction in the possibility of systemic instability.

A problem might arise, however, with the development of qualifications by the providers themselves. Although it might be expected for most programs to have equivalents at other providers, to which students could be transferred in the case of institutional failure, this might not always be the case if a PTE engages in the development of innovative programs. Any statutory provision that providers maintain transfer arrangements might safeguard the interests of students and in most circumstances would be welcomed, but might be at the expense of the dynamic creation of new courses where this could not be established. If the role of the PTEs is to create a more dynamic, innovative and competitive tertiary 
education sector then it would probably not be advisable to impose such a standard on all qualifications even if in most cases it would be of direct benefit to students and to the prevention of systemic instability.

\section{Conclusion}

The partial deregulation of the New Zealand tertiary sector would appear to have greatly assisted both the growth of the provision of tertiary education and the diversification of qualifications, programs and providers. This process can only be described as being a partial deregulation given the still extensive regulation of the sector.

Amongst other things the regulation of the sector does help to some degree to overcome the problems of information asymmetry and systemic instability without eliminating entirely the possibility of them occurring.

The protection of student's fees and the ability to transfer credit for work completed would seem to be the two main elements that protect the interests of students and reduce the possibility of systemic instability. In terms of information asymmetry the NZQA accreditation process would appear to give students some information about the quality level of a provider's programs. Despite these benefits it does not seem obvious that the regulations are specifically designed to overcome potential market failures arising from information asymmetry and systemic instability. Consequently, it is unlikely that they were expected to be entirely successful in overcoming the associated problems.

Any future review of New Zealand's tertiary education structure would do well to consider the role that regulators can play in lessening the difficulties associated with these two possible causes of market failures as well as attempt to design a regulatory structure that imposes as few costs as possible on providers and students. One approach might be to follow the lead of financial market supervision as it is presently practiced in New Zealand and require the disclosure of additional information by the education providers and NZQA itself concerning both the quality standards met by them and the financial soundness of institutions. A greater disclosure framework would allow for the further development of the tertiary education market in New Zealand, while at the same time enable students to make more informed choices about where they wish to study while at the same time provide incentives to institutions to be both educational and financially sound.

\section{References}

Abbott, M. and C. Doucouliagos (2000), 'Technical and Scale Efficiency of Vocational Education and Training Institutions: The Case of the New Zealand Polytechnics', New Zealand Economic Papers 34(1):1-24.

Boston, J. (1994), ‘The Ministerial Consultative Group’s Discussion Paper on Funding Growth in Tertiary Education and Training: A Brief Assessment', Ministry of Education, Wellington. 
Department of Education (1989), 'Learning for Life: Education and Training Beyond the Age of Fifteen Vols. I and II’, Implementation Unit, Department of Education, Wellington.

Dill, D. (1997), 'Higher Education Markets and Public Policy', Higher Education Policy 10:167-186.

Dill, D. (2000), 'Capacity Building as an Instrument of Institutional Reform: Improving the Quality of Higher Education through Academic Audits in the UK, New Zealand, Sweden and Hong Kong', Journal of Comparative Policy Analysis, Research and Practice 2:211-234.

Gemmell, N. (1997), Externalities to Higher Education: A Review of New Growth Literature, Report to the National Committee of Inquiry into Higher Education, National Committee of Inquiry into Higher Education, London.

Hawke, G. (1988), Report on Postcompulsory Education and Training in New Zealand, prepared for the Cabinet Social Equity Committee, Government Printer, Wellington.

Mora J-G., (2001), 'Governance and Management in the New University', Tertiary Education and Management 7:95-100.

Maani, S. (1997), Investing in Minds: The Economics of Higher Education in New Zealand, Institute of Policy Studies, Victoria University Wellington, Wellington.

McKenzie, D. (1996), ‘A Decade in the Life of New Zealand Universities', Education Research and Perspectives 23(1):1-21.

Maglen, L. (1990), 'Challenging the Human Capital Orthodoxy: The EducationProductivity Link Re-Examined’, Economic Record 66:281-94.

Ministry of Education (Various Issues), Education Statistics of New Zealand, Wellington.

Neal, P. (1997), 'The Wallis Inquiry: Financial Regulation and Systemic Instability', Economic Papers (2):19-27.

New Zealand Immigration Service (2004), 'Student Visa Application Statistics', Wellington.

Organisation of Economic Cooperation and Development (2002), Investment in Human Capital through Post-Compulsory Education and Training, 14 July, Paris.

Quiggin J. (1999), 'Human Capital Theory and Education Policy in Australia', Australian Economic Review 32(2):130-44.

Tertiary Education Commission (2003), Profile and Trends: New Zealand' Tertiary Education Sector 2002, Ministry of Education, Wellington. 